\title{
Ética na pesquisa com crianças: ausências e desafios*
}

\author{
NATÁLIA FERNANDES \\ Universidade do Minho, Braga, Portugal
}

\section{RESUMO}

Valendo-se da sociologia da infância, o texto discute as questões da infância, da pesquisa e da ética que devem enformar todos os procedimentos desencadeados no processo de pesquisa com crianças. Será inicialmente apresentado o estado da arte acerca das discussões que têm caraterizado esse debate, que, sendo recente, conta com uma significativa reflexão. Apresentamos, ainda, alguns desafios que são fundamentais serem enfrentados para que se consiga uma ética viável na investigação com crianças, que passam pela indispensabilidade de se pensar as questões de poder que se estabelecem entre adultos e crianças; que passam também pelo enfrentamento do desafio que decorre das hierarquias protocolares e a maneira como estas podem contribuir para a invisibilidade epistemológica das crianças na pesquisa; que passam, finalmente, por um questionamento crítico relativamente à forma como é salvaguardada a autoria, quer de crianças, quer de adultos, na análise, interpretação e produção dos dados.

\section{PALAVRAS-CHAVE}

ética na pesquisa; pesquisa com crianças; crianças; sociologia da infância.

* Texto apresentado na 36a Reunião Anual da Associação Nacional de Pós-Graduação e Pesquisa em Educação (ANPEd), sessão especial 13, subárea 5 (GT07, GT10, GT13, GT15). 


\title{
ETHICS IN RESEARCH WITH CHILDREN: ABSENCES AND CHALLENGES
}

\begin{abstract}
This paper discusses, from the sociology of childhood, the issues of childhood, research and ethics which must shape the methodological procedures undertaken in the research processes with children. We, firstly, will present the state-of-the-art theoretical discussions that have been characterizing this debate, which, although recent, are already very significant. We also present some challenges, which are essential to face, in order to achieve a feasible ethic in research with children, which are related to the need to think about the power issues between adults and children. We also have to consider that the challenge stems from the protocol hierarchies and how sometimes these can contribute to the epistemological invisibility of children in research. Finally, a third challenge that mobilizes a critical analysis related to the way issues of authorship of children and adult, in the analysis, interpretation and production of scientific texts, are respected.
\end{abstract}

\section{KEYWORDS}

ethics in research: research with children; children; sociology of childhood.

\section{ÉTICA EN LA INVESTIGACIÓN CON NIÑOS: AUSENCIAS $Y$ RETOS}

\section{RESUMEN}

Valiéndose de la sociología en la infancia, el texto discute las cuestiones de la infancia, de la investigación y la ética que deben conformar todos los procedimientos desencadenados en el proceso de investigación con niños y niñas. En primer lugar se presenta el estado de la arte acerca de las discusiones que vienen caracterizando a tal debate, que aun siendo reciente, ya cuenta con una significativa reflexión. Presentamos también algunos de los desafíos que resulta fundamental afrontar para alcanzar una ética viable en la investigación con niños y niñas, que pasan por la obligada necesidad de pensar las cuestiones de poder que se establecen entre adultos y niños; que pasan también por el afrontamiento al desafío que resulta de las jerarquías protocolarias y la forma cómo estas pueden contribuir para la invisibilidad epistemológica de los niños y niñas en la investigación. Que pasan, por fin, por un cuestionamiento crítico en cuanto a la forma como se salvaguarda la autoría, ya sea de niños o de adultos, en el análisis, interpretación y producción de datos.

\section{PALABRAS CLAVE}

ética en la investigación; investigación con niños; niños; sociología de la infancia. 
A investigação na infância, julgando processos em que as crianças são consideradas atores, com um papel mais ou menos ativo, mas sempre importante no conhecimento que se constrói acerca delas, tem uma história relativamente recente. Também assim é a história da ética na pesquisa com crianças. Em primeiro lugar, foi necessário criar espaço para a infância no discurso sociológico e depois houve que confrontar a crescente complexidade e ambiguidade da infância enquanto fenómeno contemporâneo e instável e passível de ser estudado em si mesmo, salvaguardando um conjunto de pressupostos éticos.

Como a relação entre ética e ciência tem sido continuamente renovada e reconfigurada, quer considerando os princípios epistemológicos que orientam o olhar dos pesquisadores, quer considerando as condições concretas, que em cada contexto se vão apresentando e conferindo complexidades distintas ao processo de construção de conhecimento, também assim as discussões sobre ética na investigação com crianças tem sido um constructo complexo, como apontam Gallacher e Gallagher (2008). ${ }^{1}$

Relativamente aos princípios epistemológicos, é inquestionável o contributo que documentos reguladores da ética na pesquisa têm dado, como é o caso do Código de Nuremberga de 1947, ou a Declaração de Helsínquia de 1964, os quais lançaram o debate e a reflexão acerca da salvaguarda dos direitos dos cidadãos em geral na pesquisa.

Contudo, em nossa opinião, esses documentos são portadores de algumas limitações que importa sublinhar, quando aplicados à situação concreta da infância. A primeira limitação diz respeito às áreas científicas a que se faz apelo nesses documentos, em especial no primeiro. Argumenta-se, sobretudo, a partir das ciências médicas e dos cuidados éticos que se devem salvaguardar sempre que os sujeitos são submetidos a tratamentos médicos. ${ }^{2}$ Esquecem-se, assim, os cuidados éticos que também devem ser mobilizados quando se fazem pesquisas em outras áreas, nomeadamente na área das ciências sociais, sendo a ausência ainda maior no que diz respeito à pesquisa com crianças.

A discussão sobre ética e pesquisa com crianças não tinha qualquer visibilidade, sendo quase omissos, quer documentos reguladores dessa relação, quer publicações académicas. Essa realidade começa a ser alterada a partir do momento em que se registam mudanças no paradigma com base no qual se entende/compreende a criança e a infância, lançando-se, assim, também as bases para uma renovação ético-metodológica nas relações de pesquisa com crianças.

Os primeiros textos que discutiram ética na pesquisa com crianças, em ciências sociais, datam de meados da década de 1990. São os trabalhos de Alderson (1995) que dão o mote ao início de uma discussão que ao longo desse percurso se foi intensificando e enfrentando uma invisibilidade que se tinha conseguido manter até então, sustentada, fundamentalmente, por dois argumentos. O primeiro argu-

1 As traduções são de responsabilidade da autora.

2 É interessante recuperar essa discussão na atualidade, no campo das ciências médicas, em que é possível continuar a encontrar argumentos que afastam à criança legitimidade para dar o seu consentimento informado. Conferir mais em Baines (2011). 
mento defendia a crença de que dados obtidos com crianças não eram confiáveis, uma vez que estas eram fundamentalmente definidas a partir de registos de déficits e incompetências, tal como refere Sarmento (2000, p. 157): “a criança é considerada como o não adulto, e este olhar adultocêntrico sobre a infância regista especialmente a ausência, a incompletude ou a negação das características de um ser humano "completo". Eram, portanto, dispensáveis as opiniões da crianças na construção de conhecimento acerca de seus mundos de vida, com o falacioso argumento de que elas não possuíam competências adequadas para produzir discursos relevantes acerca dos assuntos que lhe diziam respeito.

O segundo argumento sustentava um registo paternalista, ao defender que as crianças não deveriam participar nas pesquisas dada a sua vulnerabilidade e a possibilidade de poderem ser exploradas pelos pesquisadores.

Qualquer um dos argumentos propõe o afastamento da criança do processo de pesquisa, status quo que se foi mantendo, com implicação direta, também, na ausência de uma necessidade de pensar eticamente algo que não tinha qualquer estatuto ontológico e epistemológico.

E é essa invisibilidade que interessa questionar para poder criar condições básicas de inclusão das crianças na pesquisa e evitar aquilo que Santos e Meneses (2009) designam como epistemicídio do conhecimento, quando se referem ao processo de destruição da riqueza das perspetivas do saber local, da diversidade cultural e das heterogéneas visões de mundo protagonizadas por elas, que ficam subalternizadas e abafadas pela forma como o conhecimento dominante tem vindo a ser construído. No caso presente, reapropriamos esse conceito para defender que, no caso da infância, parece registar-se um eticocídio do conhecimento, pois ignora-se a ontologia ética das crianças nos processos de construção de conhecimento acerca de si, desvalorizam-se as suas perspetivas, a sua autoria e atoria social. Sem salvaguardarem-se essas pré-condições na pesquisa, todo o processo de construção de conhecimento fica inevitavelmente comprometido, bem como o estatuto atribuído às crianças nesse processo, subalternizando-se as perspetivas de uns (crianças) em detrimento de outras (dos adultos), invisibilizando dessa forma a riqueza que adviria dos seus contributos e heterogéneas visões e perspetivas.

Esse eticocídio pode assumir variados contornos, tal como defende Alderson (2004), quando identifica três imagens no estatuto ético das crianças na investigação. A primeira imagem dá conta de sujeitos desconhecidos de pesquisa, os quais estão desinformados acerca do facto de estarem a ser investigados, não lhes sendo sequer solicitado consentimento informado. A segunda imagem dá conta de sujeitos prevenidos, aos quais é solicitado consentimento informado para ser observado e/ou questionado, mas dentro de um design adulto rígido, em que tudo é decidido e controlado pelo adulto. A terceira imagem, aquela que desoculta renovadas formas de eticamente implicar as crianças na pesquisa, que é designada pela autora de participantes ativos, e dá conta de dinâmicas éticas nas quais a criança é informada acerca dos objetivos e dinâmicas da pesquisa, sendo-lhe solicitado o consentimento informado e tendo a possibilidade de influenciar a forma como decorre a sua participação. Essas três imagens podem, na contemporaneidade, coexistir, o que nos reporta para uma heterogeneidade significativa no modo como eticamente os in- 
vestigadores se comprometem, ou não, com as crianças, na forma como salvaguardam uma relação de respeito, ou não, com as crianças na pesquisa, na forma, afinal, como as valorizam enquanto sujeitos de direitos.

As mudanças a que temos vindo a assistir dão-nos conta de distintas maneiras de encarar ontológica e epistemologicamente a criança, e de traduzir tais alterações nas relações de pesquisa e no espaço de visibilidade e legitimidade que as crianças podem e passam a assumir. Com a emergência de perspetivas teóricas acerca da infância que defendem que a criança é um ator social, com uma ação socialmente relevante (Corsaro, 2005; Christensen; James, 2000; Ferreira, 2004; James; Prout, 1990; James; Jenks; Prout, 1998; Jenks, 1996; Qvortrup, 1991; Sarmento, 2004), um sujeito com direitos e um ser competente nos seus mundos de pertença, no qual estrutura relações sociais constitutivas de ordens sociais infantis (Fernandes, 2009; Tomás, 2011), edificam-se as condições para que as crianças sejam encaradas enquanto sujeitos significativos pelos/com os quais se pode construir conhecimento científico relevante.

Mobilizam-se a partir daqui novas perspetivas metodológicas no que diz respeito à pesquisa com crianças, de modo que possa ultrapassar aquilo que Woodhead (2004) denominou de "versões estreitas" sobre a criança, que até então tinham sido oferecidas pelos discursos académicos e metodologias de investigação dominantes, propondo em alternativa perspetivas interdisciplinares que sustentem abordagens integradas de investigação que reconheçam, valorizem e explicitem as múltiplas formas em que a infância é socialmente construída e reconstruída. Essas perspetivas mobilizam-nos a pensar que desenvolver pesquisas eticamente informadas com crianças implica deixar emergir um campo mais complexo no qual o investigador é confrontado com novos dilemas éticos e novas responsabilidades (Farrell, 2005).

Tal não significa uma rejeição do conhecimento tradicional e dos métodos utilizados em pesquisa ao longo dos tempos, mas sim que se considerem novas possibilidades de aceder metodologicamente às crianças, como informantes, o que implica mobilizar novos posicionamentos metodológicos e éticos respeitadores das especificidades de que se reveste a investigação com esse grupo. Significa considerar que não há uma infância homogénea, mas sim uma diversidade de infâncias; que não há métodos de investigação indiferenciados à espera de serem aplicados às crianças, mas sim que há uma heterogeneidade de possibilidades metodológicas na investigação com crianças. Significa, finalmente, que não há uma ética à la carte passível de ser replicada em cada contexto, mas sim que as relações éticas são portadoras de diversidade e complexidade e exigem um cuidado ontológico permanente de construção e reconstrução, porque a ética está ligada à construção ativa de relações de investigação e não pode ser baseada em pressupostos ou estereótipos acerca das crianças e da infância - depende, afinal, da consideração da alteridade que configura a infância.

Outro aliado nesse percurso assume uma natureza distinta, mas complementar da anterior. Estamos a falar do movimento de consolidação de direitos para as crianças, que atinge a sua maturidade no início da década de 1990, com a promulgação da Convenção sobre os Direitos da Criança, a partir da qual fica legitimada formalmente uma imagem da criança como sujeito ativo de direitos, em que é fundamental considerar sua voz e participação, bem como a salvaguarda do seu interesse superior, direitos estes que se deverem traduzir em éticas viáveis (Bell, 2008). 
Essa ética viável fundamenta um direito básico para todas as crianças, tal como defendem Beazley et al. (2009), que é o direito a ser investigado adequadamente, que tem como exigência ultrapassar um problema clássico da academia, de produção do conhecimento desligado da vida das crianças. Ora, o direito a ser investigado adequadamente, de acordo com as autoras, requer uma atenção na pesquisa que desoculte "temas, padrões, diferenças, experiências dos mundos de vida das crianças através dos tempos, espaços e culturas" (idem, p. 369).

Para tal, elas propõem que se mobilize um olhar atento para o texto da Convenção sobre os Direitos da Criança, em concreto para os seus artigos $3^{\circ}, 12,13$ e 36 . $\mathrm{O}$ artigo $3^{\circ}$, referente a um dos princípios orientadores da salvaguarda e respeito pelos direitos da criança, o seu interesse superior, permite-nos sustentar de forma consistente que em qualquer processo de pesquisa o que deve prevalecer, sobre qualquer outro princípio, é o respeito pela criança e pelas especificidades que a caraterizam ontologicamente. Também o artigo 12 da referida convenção deve ser mobilizado no intuito de considerar as opiniões e perspetivas das crianças em pesquisas que as envolvam e que lhes digam respeito, associado ao artigo 13, que permite sustentar a exigência de mobilizar métodos que permitam à criança expressar seus pontos de vista. Esses dois artigos são exponencialmente importantes para dar conta de um dos requisitos éticos mais invocados, que é o consentimento informado. Finalmente, de referir, ainda, o artigo 36, no intuito de acautelar a proteção da criança contra a exploração, ou seja, salvaguardar que as crianças não devem ser prejudicadas ou exploradas por sua participação na pesquisa.

\section{O ESTADO DA ARTE NA DISCUSSÃO CIENTÍFICA SOBRE ÉTICA NA PESQUISA COM CRIANÇAS}

Considerando o percurso que tem vindo a ser construído nos estudos da criança, em que se valoriza um papel ativo e uma centralidade da criança na pesquisa, há um aspeto que parece reunir consenso entre os investigadores: métodos e técnicas eticamente informadas adicionam valor à pesquisa e, ao mesmo tempo, a solidez metodológica pode melhorar as dimensões éticas na relação de pesquisa com as crianças (Thomas; O'Kane, 1998). Os trilhos desse percurso foram dando conta de alguns passos que, a esse propósito, assumiram visibilidade significativa no campo da ética na investigação sobre e com crianças. Apresentam-se, de seguida, alguns mapeamentos que nos permitem compreender quais têm sido os enfoques que em nível internacional têm caraterizado essas discussões.

Um dos primeiros contributos nessa discussão foi sem dúvida o dado por Alderson e Morrow (2011), com a proposta de um roteiro ético na investigação com crianças, ao identificaram aspetos importantes a serem considerados nesse processo, nomeadamente o modo como são definidos os objetivos da investigação, como são acautelados os custos e benefícios de sua realização, ou ainda como são respeitadas as questões da seleção, confidencialidade e anonimato, para além da maneira como é obtido o consentimento informado, entre outros. Discutiremos, em seguida, alguns deles.

O primeiro aspeto identificado pelas autoras tem a ver com a forma como os objetivos da investigação são definidos. Nesse sentido, quando o pesquisador define 
a sua investigação, deverá questionar-se relativamente à utilidade que a investigação assegura bem como os interesses que são considerados na pesquisa.

O segundo aspeto tem a ver com os custos e benefícios associados à pesquisa. Nessa dimensão, deve questionar-se se as crianças poderão correr alguns riscos ou suportar custos, nomeadamente no que diz respeito a tempo, inconveniência ou embaraço. Deve questionar-se se a pesquisa acautela a possibilidade de as crianças poderem beneficiar com a sua participação na pesquisa, nomeadamente com satisfação, aumento de confiança ou conhecimento, entre outros.

Um terceiro aspeto tem a ver com as questões de privacidade e confidencialidade. Essas questões envolvem diferentes momentos da pesquisa. Desde seu início, acautelando-se a forma como se obtém o acesso às crianças e como se salvaguarda que elas possam optar desistir da pesquisa, ou então de que forma se salvaguarda na pesquisa mecanismos de desistência que não sejam intrusivos. Devem ainda se acautelar os espaços onde a recolha de informação decorre, de modo que não haja ruídos ou intromissões que condicionem a recolha da informação. Há que considerar nesse aspeto uma questão com alguma complexidade, que deverá equacionar a possibilidade de serem divulgados episódios reveladores de risco para as crianças e a forma como os pesquisadores lidam com a informação recolhida. São complexas as soluções, mas elas devem contemplar, por um lado, a relação de confiança estabelecida entre investigador e crianças e, por outro lado, a exigência que qualquer adulto tem no sentido de proteger a criança. É, ainda, relevante considerar nesse aspeto questões relacionadas com a utilização dada ao material recolhido durante o processo de investigação, sejam notas, gravações, filmes da pesquisa ou outros materiais para proteger o anonimato e a confidencialidade dos informantes.

Um quarto aspeto considera a forma como são selecionados os participantes na pesquisa. Como salvaguardar o princípio da não exclusão nesse processo é a grande questão. Como se justifica a inclusão de uns e a exclusão de outros é um aspeto que o investigador deve acautelar, de modo que seja respeitoso com todas as crianças.

Um quinto aspeto tem a ver com o consentimento informado. De acordo com Morrow (2005), o consentimento é um processo pelo qual alguém, voluntariamente, concorda em participar de um projeto de investigação baseado na análise de informação pertinente. Nesse processo, há um conjunto de aspetos a ter em conta para o dotar de critério e rigor, nomeadamente: é fundamental que aos participantes seja providenciada informação relevante para que possam ter opiniões sustentadas acerca do processo; é fundamental que se assuma enquanto ato explícito, ou seja, que se concretize em um momento em que os participantes tenham a possibilidade de apresentar o seu acordo, que pode ser verbal ou escrito; ${ }^{3}$ é fundamental que seja voluntário, sem provocar na criança qualquer sentimento de coerção, tornando sem-

3 O consentimento das crianças pequenas é algo que começa a ser discutido em ciências sociais e que nos mobiliza a desencadear outros modos de o respeitar, tal como refere Coutinho (2010, p. 18): "A aceitação das crianças também era considerado um aspeto central; no entanto, a análise dessa dimensão só seria possível após a entrada no campo, tendo em vista que com as crianças bem pequenas o 'Termo de Consentimento Informado' é dado pelos responsáveis legais, no caso desse grupo os pais ou as mães e a 
pre explícito que pode ser constantemente renegociado e renovado, criando com a criança mecanismos que the permitam abandonar a processo em qualquer momento.

O consentimento informado tem sido um dos aspetos éticos mais intensamente discutido nos últimos tempos. Dingwall (1980), a esse propósito, defende que é imprescindível considerar uma hierarquia de consentimentos, uma complexidade de escolhas e de constrangimentos situacionais e um conjunto de códigos de conduta que envolvem certas expectativas mútuas, o que exige um processo constante de reflexividade para acautelá-los. Também Ferreira (2010, p. 1) nos ajuda a encarar a questão do consentimento de uma forma criteriosa e respeitadora para as crianças quando defende:

A análise de algumas configurações que o assentimento e as recusas por parte destas crianças podem assumir ao longo da pesquisa procura evidenciá-los como um processo contingente, heterogéneo e dependente da relação social de investigação que vai sendo construída, bem como das interpretações que as crianças tecem acerca da pessoa da investigadora.

Esse é, assim, um aspeto que exige uma constante reflexividade, considerando sempre que os protocolos, tal como os procedimentos, não são fixos, mas sim permanentemente ativos e renegociados, devem considerar as características das crianças e dos adultos envolvidos, bem como as características que enformam os seus mundos de vida. Devem, nesse processo, considerar-se os conceitos de "ação" e de "competência" e incorporar outros como a incompetência, a dependência, a imaturidade e a incompletude (adultos/crianças), que são aspetos inerentes à ambiguidade ontológica dos sujeitos envolvidos, quer sejam adultos, quer sejam crianças, e necessários para compreender alguns dos desassossegos que se colocam nas pesquisas.

$\mathrm{O}$ respeito por todos esses aspetos assume-se como um desafio acrescido se considerarmos que há outras dimensões que têm de ser consideradas em simultâneo, nomeadamente as questões etárias, que não sendo determinantes e estáticas no que diz respeito às competências das crianças, exigem um olhar atento que saiba respeitar e valorizar as heterogéneas competências de cada criança nesse processo. Essas competências estão profundamente implicadas com as experiências das crianças, com o seu background sociocultural e económico, bem como ainda com as questões de género, religião, com as próprias questões da investigação, do contexto da investigação e ainda dos métodos de pesquisa utilizados.

As discussões sobre os modos como esses e outros aspetos éticos estão sendo (ou não) respeitados na pesquisa com crianças têm sido alvo de reflexão na academia, em que se apresentam argumentos e contra-argumentos a esse propósito, tendo, no entanto, sempre como denominador comum a defesa de que a salvaguarda é fundamental na edificação de uma relação de respeito com a criança, na qual seja defendido, em qualquer momento, o seu interesse superior. É esse estado de arte que de seguida apresentamos.

aceitação dos bebés em relação à presença da investigadora e do registro das suas ações ocorre no desenrolar do trabalho, de modo sutil e partilhado". 
A esse propósito, Francischini e Fernandes (2013), ${ }^{4}$ em levantamento bibliográfico sobre o tema, identificam algumas das nuances que têm caracterizado as produções dos investigadores em estudos da criança sobre ética na pesquisa com crianças. Desde logo, o facto de a imagem de criança dominante em todos os trabalhos analisados ser a imagem da criança como ator social e sujeito de direitos, em que é reconhecida a sua competência para se expressar e produzir interpretações sobre a realidade, objetos ou eventos. No que diz respeito aos aspetos éticos específicos, na literatura analisada é nítida a prevalência da reflexão sobre o consentimento informado e assuntos relacionados com ele, sobre outros aspetos éticos, nomeadamente a confidencialidade ou a própria devolução da informação. É também relevante a discussão que emerge dos textos analisados acerca do posicionamento do investigador, sendo muito recorrente a discussão sobre o poder, bem como das diferenças entre investigador e investigados. Finalmente, outro assunto presente nesses textos tem a ver com o papel dos comités de pesquisa e a forma como estes protegem ou não a participação das crianças na pesquisa.

Powell et al. (2012), também em uma revisão internacional de literatura a propósito das questões éticas consideradas na pesquisa com crianças e jovens, avançam com algumas afirmações importantes. De acordo com os autores, há quatro aspetos que recorrentemente aparecem na literatura: a questão do consentimento informado; a questão da proteção contra o dano; a questão da confidencialidade e anonimato e a questão do pagamento pela participação na pesquisa.

No que diz respeito ao consentimento informado, é referido pelos autores que esse é o cuidado ético mais amplamente discutido, aparecendo na literatura com quatro exigências: de que o consentimento envolva um ato explícito, por exemplo, um acordo verbal ou escrito; de assegurar que pode ser dado se os participantes forem informados e conhecerem a pesquisa; de assegurar que ele aconteça de forma voluntária e sem coerção; e, finalmente, de poder ser renegociável para que as crianças possam desistir em qualquer momento da pesquisa.

Um segundo aspeto tem a ver com a proteção das crianças contra qualquer dano, sendo importante a discussão acerca das dificuldades de definir limites a esse propósito em ciências sociais. Alguns autores têm vindo a falar sobre as dificuldades que as hierarquias de cuidadores colocam à pesquisa (Hill et al., 2004; Hood; Kelley; Mayall, 1996; Masson, 2004; Powell; Smith, 2009), cuja intenção é a genuína preocupação de proteger a criança, mas quando amparado por um forte discurso protecionista pode negar à criança o direito de expressar suas opiniões.

4 Publicações referidas na International Society of Sociology (ISA) e na European Society of Sociology (ESA). No site dessas duas associações, foram identificadas as publicações que apresentavam, em seus resumos (abstracts), a expressão "sociology of childhood". Os períodos compreendidos foram de março/1986 a dezembro/2012 e janeiro/1980 a dezembro/2012, disponibilizados, respectivamente, pela ISA e pela ESA. Foram identificados, na ISA, 20 artigos, e na ESA, 22. Foram excluídas as publicações de apresentações e/ou comentários de livros. Foram consideradas as publicações nas quais os autores discutiam explicitamente as questões relacionadas com a ética na pesquisa com crianças, tendo assim registado 6 dos 42 artigos lidos. 
Retomaremos essa reflexão mais à frente, quando discutirmos os desafios para uma ética viável na investigação com crianças.

As questões relacionadas com a confidencialidade são também frequentes na literatura sobre ética na investigação com crianças, quer questionando os espaços onde se realiza a pesquisa, quer a forma como são assegurados o anonimato e a confidencialidade. A propósito desse último aspeto, tem vindo a ser discutido em fóruns os dilemas que surgem a respeito dos limites da confidencialidade, sempre que estejam em causa questões de proteção e segurança das crianças, mas esse é um assunto sobre o qual não há, ainda, consensos. ${ }^{5}$ De referir, ainda, um outro aspeto que continua a levantar alguma controvérsia nesse campo e que diz respeito ao pagamento ou não da participação das crianças na pesquisa ou à forma como se lhes retribui o tempo gasto com a pesquisa, sendo a esse respeito grandes as divergências, tendo em conta o contexto cultural onde ela ocorre. Se em determinados contextos esta poderá parecer uma não questão, dadas as condições de salvaguarda de direitos básicos de provisão e proteção das crianças, o mesmo já não acontece quando realizámos pesquisa com crianças que dependem do seu próprio trabalho para que tais direitos possam ser minimamente satisfeitos.

Como se pode verificar dos mapeamentos que apresentámos, há questões recorrentes nos modos como a pesquisa com crianças se vai sustentando eticamente, que assumem contornos bem heterogéneos, mediante os contextos e os atores envolvidos, que atribuem à ética uma complexidade assinalável e uma dificuldade substantiva de a salvaguardar na pesquisa com crianças. Será, porventura, útil, mobilizar as três dimensões que Alderson e Morrow $(2011)^{6}$ identificam no seu trabalho a esse propósito: os direitos, os deveres e os riscos/benefícios.

No primeiro - direitos -, as autoras sublinham a importância de respeitar os direitos dos participantes na pesquisa, salvaguardando o princípio da não interferência e da não intrusão, bem como a prevenção e a proteção de qualquer possibilidade de dano, negligência ou discriminação. No segundo - deveres -, fazem referência às cautelas relativas, ou seja, garantir que a pesquisa possa ser útil e não provoque danos aos participantes, sendo para tal necessário ponderar benefícios e constrangimentos que resultem do seu processo, bem como ainda a ressalva de um tratamento respeitoso e justo. Finalmente, no que diz respeito à terceira dimensão - riscos/benefícios -, torna-se importante ponderar de que maneira se respeitam os interesses de todos os envolvidos e as suas prioridades. Em uma pesquisa com crianças, qual o interesse a prevalecer: $\mathrm{O}$ da criança? $\mathrm{O}$ dos seus pais? $\mathrm{O}$ do pesquisador? $\mathrm{Ou}$ o da sociedade?

As mesmas autoras defendem, ainda, que em qualquer dessas três dimensões há vantagens e limites. Defendem, por um lado, que a ética não nos faculta soluções claras e consensuais, assumindo maior utilidade enquanto método para explorar dilemas, que permitem compreender os problemas mais claramente e com maior profundidade. Consideram ainda que não há qualquer consenso relativamente à

5 Ver a propósito o texto de Cashmore (2006).

6 Ver a propósito os trabalhos de Alderson (2004); Alderson e Morrow (2011); Morrow (2005, 2008); Morrow e Richards (1996). 
hierarquia de importância que cada uma das três dimensões pode assumir, ao que nós propomos que tal se deve exercitar pelos processos de reflexividade que priorizem o interesse superior da criança na tomada das decisões consideradas mais adequadas para a pesquisa, para evitar quer sentimentos de exclusão, intrusão ou exposição das crianças nesses processos, que deverão ser, sobretudo, processos justos, isentos e promotores de bem-estar para os envolvidos.

De forma que possa lidar com as complexidades que resultam desses limites e constrangimentos, as mesmas autoras propõem que é necessário desenvolver

[...] novas formas de pensar a ética na pesquisa com crianças. A ética tradicional sublinha com razão a importância da não interferência e evitar causar dano deliberado, mas pouco é dito acerca dos perigos que advêm da sobreproteção das crianças ao silenciá-las e excluí-las da pesquisa. (idem, p. 19)

$\mathrm{Na}$ esteira das autoras, o que propomos agora é mobilizar alguma reflexividade nessas novas formas de pensar a ética na pesquisa com crianças, com a consideração de alguns desafios para uma ética viável com crianças que nos ajudem a ter cautelas éticas e epistemológicas, ou, tal como defende Santos (2003), a ter um pensamento prudente, a fim de evitar os enganos de uma razão indolente.

\section{DESAFIOS PARA UMA ÉTICA VIÁVEL NA INVESTIGAÇÃO COM CRIANÇAS}

Do explanado até agora, pudemos perceber um percurso importante na superação do eticocídio a que fazíamos referência na parte inicial do texto. De facto, ao longo das últimas décadas, assistiu-se a um investimento académico, sobretudo amparado pelos estudos da infância ou da criança, que colocou na agenda da pesquisa as crianças e as questões éticas que lhe são inerentes, recolocando-as como sujeitos ontologicamente importantes e metodologicamente relevantes, processo este informado eticamente por um conjunto de pressupostos a que já fizemos referência.

A questão que agora levantamos nos mobiliza a pensar em formas mais reflexivas de respeitar não somente os importantes preceitos éticos, que começam a fazer parte do discurso dominante em pesquisa, mas também conseguir que tais preceitos se concretizem em uma ética viável e significativa para as crianças. A esse propósito, identificamos três aspetos que gostaríamos de discutir com mais detalhe: as questões de poder e a forma como elas devem ser mobilizadas nesse processo; as hierarquias protocolares e a (in) visibilidade epistemológica das crianças na pesquisa; e, finalmente, discutir as questões da autoria das crianças e dos adultos nos textos de pesquisa, ou seja, discutir de que forma a ética é também importante nos momentos de análise e interpretação dos dados.

\section{AS QUESTÕES DO PODER}

Nas relações de pesquisa que se estabelecem com as crianças, para além dos dilemas éticos que colocam, exigem uma postura atenta relativamente às relações de 
poder que aí se jogam, nas quais crianças e adultos assumem papéis e "espaços" que não devem ser naturalizados, mas sim questionados. Como sabemos, um dos aspetos que mais frequentemente caraterizam as relações entre adultos e crianças é a relação hierárquica em que o adulto sobressai como aquele que possui mais conhecimento, mais experiência e, por tal, possui também o poder de decidir, de mandar. $\mathrm{O}$ adulto é, nessa relação, a figura do poder. Quando o poder é encarado como uma maneira de controlo, quando os investigadores utilizam o seu poder enquanto adultos, não prescindindo dele, nem o acautelando nas relações de investigação que estabelecem com as crianças, para atingirem determinados objetivos científicos, as dinâmicas de investigação que daí decorrem dificilmente poderão ser consideradas dinâmicas informadas eticamente.

A sociologia da infância tem vindo a discutir esse aspeto desde há algum tempo, no intuito de não se assumir tacitamente essa relação hierárquica e se pensar em formas alternativas de construir relações de pesquisa com as crianças, que sejam mais horizontais e respeitadoras da criança enquanto ator social. Christensen (2004) defende a este propósito que é fundamental considerar as questões de poder como inerentes ao processo de investigação, uma vez que "a pesquisa é uma prática que faz parte da vida social. Tal requer que o pesquisador preste atenção a assuntos mais abrangentes da vida social e cultural, que são, ou podem ser, sensíveis à questão do poder" (idem, p. 166). A autora defende, ainda, que é importante ultrapassar a ideia de que o poder está alojado em categorias, nesse caso, geracionais, de "adulto" e de "criança", para passar a considerar que ele está sobretudo dependente das representações sociais que cada um tem acerca da alteridade do outro, o que tem implicações diretas na forma como se faz, se negocia, se pesquisa, afinal. Remete-nos, assim, para a importante ideia que Foucault (2002) anunciava de que o poder não existe, o que existem são relaçôes de poder, devendo portanto questionar-se reflexivamente a maneira como nós, enquanto adultos investigadores, construímos a relação de investigação com a criança para salvaguardar que sua participação na pesquisa - a proteção de preceitos éticos, como o são a sua inclusão no projeto ou o seu consentimento informado, entre outros aspetos - possa ser exercida pela criança de uma forma livre. Concordamos, ainda assim, com Morrow e Richards (1996, p. 98) quando defendem que "O maior desafio ético para os investigadores que trabalham com crianças é a disparidade de poder e estatuto entre adultos e crianças". Há a convicção de que a forma como o adulto assume o controlo dos processos nas relações com as crianças e jovens é, ainda, reveladora de relações de poder desiguais; há, também, a convicção de que estas relações de poder desiguais são replicadas se não duplicadas nos processos de investigação (Harden et al., 2000; Morrow; Richards, 1996; Punch, 2002).

A esse propósito, McCrum e Bernal (1994) elencam algumas questões que poderão ser orientadoras de alguma mudança a esse respeito, nomeadamente a necessidade de questionar até que ponto as crianças se sentem livres para recusar participar de um estudo, livres para abandonar a investigação e, ainda, até que ponto dão as suas próprias opiniões e partilham experiências com os pesquisadores adultos sem se sentir constrangidas e influenciadas na forma como produzem (ou não) com autoria suas representações. 
Também Kirk (2007) apresenta um conjunto de estratégias para enfrentar metodologicamente as questões de poder nas relações de investigação, passando pelo uso de métodos que permitem às crianças sentir que fazem parte do processo de investigação, no qual têm possibilidade de apresentar seus pontos de vista; com pesquisadores que sejam sensíveis às agendas das crianças; que estejam vigilantes relativamente à disponibilidade das crianças para participarem em todo processo da pesquisa, sendo importante ensaiar com elas as possibilidades/dinâmicas sobre como recusar participar no processo de pesquisa.

Para além dessas propostas mais prescritivas, gostaríamos de rematar essa abordagem às questões do poder nas relações de pesquisa com crianças com uma proposta de Lee (2001) e Horton (2001) sobre a reabilitação crítica do conceito de imaturidade metodológica na pesquisa com crianças. Os autores defendem que, tal como "tornar-se", "imaturidade" tem sido bastante sublinhada no novo paradigma da investigação acerca da infância, vista como um produto inútil na hierarquização do binário adulto-criança.

Se considerarmos que todos os indivíduos são seres em construção, também todos são, nesse sentido, imaturos, o que não pode ser encarado de forma negativa, mas sim como um potencial. Ao enfatizar dependência, incompetência, incompletude e vulnerabilidade, o conceito de imaturidade tenta apresentar a investigação social como um processo necessariamente complexo, incompleto e confuso. Tal atitude tem o potencial de enfrentar as noções dualistas dos pesquisadores poderosos e dos participantes vulneráveis, dos adultos competentes e das crianças incompetentes.

Se os pesquisadores fossem totalmente maduros, eles saberiam todas as respostas; se eles conhecessem todas as respostas, não necessitariam fazer pesquisa. $\mathrm{O}$ nosso posicionamento enquanto investigadores adultos deverá considerar que as crianças possuem informações importantes, que não será possível alcançar de outro modo que não seja por meio de sua voz e ações, sendo fundamental criar espaços e tempos para que tal possa ocorrer.

Assim, pensar em uma subjetividade emergente, que enfatize mais os processos que os produtos, que não os reduza a regras e técnicas previamente e estritamente estabelecidas pelo adulto pesquisador, mas sim que promova processos dialógicos que impliquem crianças e adultos na construção do processo poderá ser um contributo importante para ultrapassar esse desafio ético.

\section{HIERARQUIAS PROTOCOLARES E A (IN)VISIBILIDADE EPISTEMOLÓGICA DAS CRIANÇAS NA PESQUISA}

O debate acerca da ética remete-nos para duas direções. Uma considera a importância da existência de regulamentos e códigos éticos ou, mais modestamente, a formulação de princípios éticos. A outra enfatiza a responsabilidade individual e as competências pessoais do investigador por meio de uma perspetiva de contínua reflexibilidade acerca de sua própria prática. Os princípios e códigos éticos são importantes, mas não são suficientes para abarcar todas as complexidades com que o investigador se confronta no texto de investigação. 
Um desafio que emerge da sistematização e codificação da ética em preceitos e entidades que regulam o instituído tem a ver com os possíveis efeitos referentes à (in)visibilidade das crianças na pesquisa. De acordo com Allen (2005 apud Furedi, 2002).

Para muitas instituições, e também para muitas entidades reguladoras, a ética na pesquisa tornou-se, tão somente, em um processo cauteloso de gestão do risco. Como consequência, os comités de pesquisa podem assumir posições extremamente conservadoras nas propostas de pesquisa, especialmente quando os designs da pesquisa são mais inovadores.

A esse propósito, Powell et al. (2012) referem, também, que tem sido crescente o questionamento acerca do reducionismo que pode advir das salvaguardas éticas na pesquisa, se limitarem tal à mera salvaguarda de um conjunto de princípios codificados.

Daqui pode resultar a impossibilidade de desenvolver trabalho empírico importante e valioso, subjugado ao preceito da necessidade de proteção do sujeito, nesse caso a criança, acentuando-se as suas vulnerabilidades e mantendo-se, dessa forma, invisíveis a sua voz.

Allen (2005) propõe-nos uma perspetiva mais abrangente do que se deve ser considerado em um processo de pesquisa eticamente informado. Defende o autor que, para tal, não podemos reduzir o processo a mero ato de preenchimento de formulários ou do acautelar e gerir riscos. Em sua opinião, teremos de considerar três níveis na gestão da conduta ética em pesquisa: o nível regulatório, o nível institucional e o nível pessoal.

No nível regulatório estão contemplados os códigos e regulamentos éticos. Nesse nível, passou-se, nas últimas décadas, de orientações definidas por alguns investigadores para códigos de conduta mais diretivos que articulam também responsabilidades institucionais. Esses códigos têm, crescentemente, vindo a ser aplicados e definem conceitos bem delimitados do que significa o desenvolvimento de pesquisa nessas áreas, em grande parte influenciados pelos princípios éticos das áreas biomédicas.

No nível institucional, regista-se o papel que assumem as instituições e a crescente visibilidade de comités éticos, com a consequente burocratização do processo, nos quais as dimensões administrativas e políticas assumem uma considerável importância nos modos como a cultura ética é construída em cada instituição.

Há, no entanto, alguns riscos nesse gradual interesse institucional acerca das questões éticas, havendo casos em que a pesquisa pode ficar condicionada, nomeadamente em casos em que é feita uma gestão desequilibrada dos riscos e benefícios, ao valorizar-se a gestão do risco de exposição em detrimento de aspetos mais substantivos, como é, por exemplo, a importância dos contributos advindos da participação das crianças para o conhecimento que é produzido acerca de si.

No nível pessoal, é importante considerar o papel central que o pesquisador tem nessa questão, uma vez que grande parte das questões éticas surge no decurso da relação de pesquisa, durante a qual o investigador é confrontado com desafios 
éticos que exigem tomadas de decisão no momento, profundamente dependentes das subjetividades que cada um coloca na salvaguarda das dimensões éticas.

É, portanto, nessa multidimensionalidade que se joga a ética na investigação com crianças. Uma gestão complexa em que alguns dos níveis podem comprometer outros e, dessa forma, comprometer a própria construção de conhecimento.

É fundamental, portanto, acautelar no processo de pesquisa que as hierarquias protocolares não invisibilizem epistemologicamente as crianças, aspeto que na nossa opinião depende, em grande parte, da forma como os três níveis propostos por Allen (2005) comunicam entre si. Trata-se, em nossa opinião, da exigência de considerar em cada um desses três níveis uma imagem de infância partilhada, que considere as crianças como sujeitos, e não como meros objetos, que considere que o processo de pesquisa com crianças não deve ficar refém meramente do que está institucionalizado, sob pena de não avançarmos no processo de construção de conhecimento. Sob pena, afinal, de alimentarmos uma invisibilidade epistemológica da criança.

\section{ENTRE A AUTORIA DA CRIANÇA E A AUTORIA DO ADULTO...}

$\mathrm{Na}$ discussão sobre ética na pesquisa com crianças, essa é, sem dúvida, a dimensão menos considerada e discutida. Poucos são os textos que discutem os modos como nos devemos acautelar eticamente na análise, na interpretação e produção dos textos científicos a partir daquilo que as crianças nos dizem durante a fase da recolha de informação. A esse propósito, $\operatorname{Kramer}(2002$, p. 42) refere que:

Quando trabalhamos com um referencial teórico que concebe a infância como categoria social e entende as crianças como cidadãos, sujeitos da história, pessoas que produzem cultura, a ideia central é a de que as crianças são autoras, mas sabemos que precisam de cuidado e atenção.

James (2007) alerta-nos, também, no sentido de acautelar o facto de que dar voz às crianças não significa simplesmente deixar que elas falem, tratando-se antes de explorar o contributo único que tal dá à compreensão e teorização acerca do mundo social. Para a autora, o problema da representação é central na questão da "voz", o que exige da parte dos pesquisadores uma reflexividade crítica acerca do seu papel no processo de a representarem, defendendo que "Refletir acerca das complexidades que enquadram o que as crianças dizem, em vez de simplesmente defender que registar e gravar a sua voz é suficiente, poderá ser uma estratégia para que as vozes das crianças possam ser realmente compreendidas" (idem, p. 270).

Outra autora, Komulainen (2007), falando acerca da ambiguidade que a voz da criança pode assumir na pesquisa social, defende uma desconstrução do conceito de "voz", compreendido como uma construção social multidimensional, sujeita a mudanças, porque a voz é reveladora ao mesmo tempo dos discursos, das práticas e contextos onde ocorre. Komulainen, baseando-se em Bakhtin, defende que as vozes são sempre sociais, sendo fundamental colocar em discussão, no conhecimento que resulta do desenvolvimento de investigação com crianças, quer a autoridade, quer a autoria. A autora chama atenção para o facto de que, apesar de as palavras das 
crianças, que aparecem nos relatórios, poderem ser apresentadas como autênticas, coloca-se o caso de elas poderem ser escolhidas pelo pesquisador e poderem ser colocadas no texto para ilustrar um argumento ou sublinhar um ponto de vista, sendo dessa forma expresso o ponto de vista do pesquisador e não o da criança. Sendo os adultos que escrevem os textos, são eles que detêm o poder sobre as vozes das crianças. Levanta-se, portanto, com muito critério uma exigência ética, da parte do pesquisador, no sentido de ser mais cauteloso e consciente acerca da forma como, por um lado, mobiliza as vozes das crianças e, por outro lado, como acautela que essas mesmas vozes poderão ser constrangidas e moldadas por diversos fatores, tais como as assunções que temos acerca das crianças, a forma como utilizamos a linguagem, os contextos institucionais em que nos movemos etc. Ou seja, para Komulainen, o uso das vozes das crianças como evidência necessita ser considerado com cautela, atendendo aos contextos culturais da sua produção, devendo ser compreendidas em suas particularidades, devendo a sua autenticidade ser interrogada e contextualizada, a sua autoria não deturpada, sob pena de ficarem mascaradas e o conhecimento que daí resultar expressar mais autoria do adulto que da criança.

Outro autor que contribui para essa discussão é Spyrou (2011, p. 151). Ao argumentar que tendo os estudos da criança construído sua razão de ser à volta do conceito de "voz" da criança, afirma que "essa preocupação, bem recebida, quer em termos metodológicos, quer em termos éticos, falhou fundamentalmente em considerar de uma forma crítica as questões da representação”. O autor levanta, a partir dessa afirmação, algumas interrogações que nos parecem bastante úteis para, criticamente, considerar a questão da autoria no texto científico. Uma delas questiona o tipo de enquadramentos e categorias que o pesquisador aplica na análise das vozes das crianças, ou seja, "se os pesquisadores tentam enquadrar dentro de suas categorias semânticas os dados recolhidos para atribuir sentido ao que as crianças lhes contam, ou se, pelo contrário, há espaço para que a semântica da criança emerja” (idem, p. 158). Se tal não acontecer, se a semântica do adulto se sobrepuser à semântica da criança, tudo aquilo que a criança diz pode ser utilizado ao serviço do que o adulto entende ser o que a criança quis dizer.

Spyrou alerta-nos, ainda, para a necessidade de considerar profundamente insuficiente a sinalização das vozes, como cuidado único para as tornar visíveis nos textos que se produzem. De acordo com o autor, é fundamental identificar as vozes, mas é igualmente fundamental situá-las devidamente nos campos discursivos de poder em que são produzidas.

De forma que produza relatórios de pesquisa eticamente informados é, então, basilar questionarmo-nos acerca da forma como as vozes das crianças são colocadas, mobilizando cautelas epistemológicas e éticas que permitam um olhar crítico e reflexivo, tentando salvaguardar todas as possibilidades de o pesquisador não se deixar influenciar na interpretação e produção de conhecimento com as agendas ocultas, com motivos e/ou interesses implícitos, com assunções ideológicas, entre outros aspetos. 


\section{CONCLUINDO}

Em uma era em que crescentemente se tem vindo a reconhecer a criança enquanto ator social e a sua competência para participar na pesquisa, estamos também a assistir a um crescente interesse à volta das questões éticas que envolvem a pesquisa.

Pudemos perceber, pelos contributos que fomos convocando ao longo deste texto, que falar de ética na pesquisa com crianças não implica somente ter cuidados na forma como se planifica essa pesquisa, na forma como testamos e analisamos a vida dessas crianças, mas implica, sobretudo, atender aos modos como desencadeámos processos dialógicos e ponderados, de forma que se possa respeitá-las ontologicamente em sua alteridade, pois somente desse modo é possível assegurar que nos processos de pesquisa co-construídos entre o pesquisador e as crianças asseguremos que "não é suficiente que um resultado seja eticamente aceitável ou desejável; os meios para o atingir devem, também, ser éticos" (Somerville, 2006, p. 25).

$\mathrm{Na}$ procura desses meios, há algumas cautelas epistemológicas que nós, enquanto pesquisadores, deveremos mobilizar em permanência, nomeadamente a ideia de imaturidade metodológica defendida por Lee (2001) e Horton (2001). Quando construímos com as crianças possibilidades de discutir e negociar o processo de investigação, devemos, sempre, estar preparados para as complexidades que daí advêm, pois a imaturidade da criança é algo que não pode ser assumido como tácito, tal como a imaturidade do pesquisador adulto. Elas coexistem em um tempo-espaço e exigem, principalmente do adulto, competências de enfrentamento que respeitem diferentes alteridades e imaturidades, não as subsumindo na homogeneidade que, por vezes, a ética, em sua vertente institucionalizada, quer fazer valer.

Para rematar, deixamos a transcrição de um episódio revelador, em nossa opinião, da maturidade (in)esperada da criança, ${ }^{7}$ que em processos de pesquisa poderá interpelar o adulto investigador em suas supostas (in)competências:

- Que cena, esta pergunta: se nós queremos! Não queres que a gente te diga que não, pois não?

- Tu é que decides se queres participar no estudo, és tu quem escolhes. Eu só te estou a perguntar se realmente queres participar ou não, e se quiseres podes sempre optar por desistir no decorrer do processo!

- Eu não disse que não queria!

- Mas disseste que eu não ia gostar se vocês optassem por não participarem, não foi?

- Foi, mas esquece! Claro que quero participar! Vais dar alguma coisa depois a nós?

$-[\ldots]$

- Tá bem! Eu tava na tanga contigo! Vá! Ainda por cima quem manda sou eu! (Santos, 2011, p. 70)

7 Yasmin, 11 anos (nome fictício). 
Entre as demandas éticas institucionais e aquelas que se estabelecem na relação com o outro-criança no processo de pesquisa, o pesquisador não tem, indiscutivelmente, uma tarefa simples. O caminho da pesquisa com crianças será sempre marcado pelo inesperado que advém da alteridade que carateriza a categoria geracional da infância. Mas será no respeito que assegura e na relação que estabelece com esse inesperado que reside o maior contributo que o investigador pode dar para a construção de conhecimento, eticamente sustentado, na infância.

\section{REFERÊNCIAS}

Alderson, P. Listening to children: children, ethics, and social research. Essex: Barnardos, 1995.

.Ethics. In: Fraser, S.; Lewis, V.; Ding, S.; Kellett, M.; Robinson, C. (Eds.). Doing research with children and young people. London: Sage Publication, 2004. p. 97-112. .; Morrow, V. The ethics of research with children and young people: a practical handbook. London: Sage, 2011.

Allen, G. Research ethics in a culture of risk. In: Farrell, A. (Ed.). Ethical research with children. 8. ed. London: Open University Press, 2005. p. 15-26.

Associação Médica Mundial. A Declaração Helsinque. [S.1.: s.n.], 1964.

Baines, P. Assent for children's participation in research is incoherent and wrong. Archives of Disease in Childhood, 2011. Disponível em: <http://adc.bmj.com/content/ early/2011/07/19/adc.2011.211342.short?rss=1>. Acesso em: 14 abr. 2016.

Baкнtin, M.(Volochinov, 1929). Marxismo e filosofia da linguagem. Tradução de Michael Rahud e Yara Frateschi Vieira. São Paulo: Hucitec, 1990.

BeAZley, H.; Bessel, S.; Ennew,J.; Waterson, R. The right to be properly researched: research with children in a messy, real world. Children's Geographies, London: Taylor \& Francis, v. 7, n. 4, p. 365-378, 2009.

BELL, N. Ethics in child research: rights, reason and responsibilities. Children's Geographies, London: Taylor \& Francis, v. 6, p. 7-20, 2008.

CAshmore, J. Ethical issues concerning consent in obtaining children's reports on their experience of violence. Child Abuse \& Neglect, London: Sage, v. 30, n. 9, p. 969-77, 2006.

Christensen, P. Children's participation in ethnographic research: issues of power and representation. Children \& Society, Hoboken, NJ: Wiley-Blackwell, v. 18, n. 2, p. $165-176,2004$.

.; JAmEs, A. (Eds.). Research with children: perspectives and practices. London: Routledge, 2000.

Corsaro, W. The sociology of childhood. 2. ed. Thousand Oaks: Pine Forge Press, 2005. Coutinno, A. M. S. A ação social dos bebês: um estudo etnográfico no contexto de creche. 2010. Tese (Doutoramento em Estudos da Criança) - Universidade do Minho, Braga, 2010. Dingwall, R. Ethics and ethnography. Sociological Review, Hoboken, NJ:Wiley-Blackwell, v. 28, n. 4, p. 871-891, 1980. 
Fernandes, N. Infância e direitos: representações, práticas e poderes. Porto: Afrontamento, 2009.

Ferreira, M. “A gente gosta é de brincar com os outros meninos!" Relações sociais entre crianças num jardim de infância. Porto: Afrontamento, 2004.

“- Ela é a nossa prisioneira!” Questões teóricas, epistemológicas e ético-metodológicas a propósito dos processos de obtenção da permissão das crianças pequenas numa pesquisa etnográfica. Reflexão e Ação, Santa Cruz do Sul: EDUNISC, v. 18, n. 2, p. 151-182, 2010.

Foucault, M. Microfísica do poder. Rio de Janeiro: Graal, 2002.

Francischini, R.; FERnandes, N. Ética e pesquisa com crianças: questões e desafios desde a sociologia da infância. 2014 (no prelo).

Furedi, F. Dont' rock the research boat. Times Higler Education Supplement, United Kingdon: TES Global, n. 11, p. 20, jan. 2002.

Gallacher, L. A.; Gallagher, M. Methodological immaturity in childhood research? Thinking through participatory methods. What are "participatory" methods, and why do we need them. Childhood, London: Sage, v. 15, n. 4, p. 499-516, 2008.

Harden, J.; Scott, S.; Backett-Milburn, K.; Jackson, S. Can't talk, won't talk? Methodological issues in researching children. Sociological Research Online, v. 5, n. 2, 2000. Disponível em: <www.socresonline.org.uk/5/2/harden.html>. Acesso em: 14 abr. 2016.

Hill, M.; Davies, J.; Prout, A.; Tisdall, K. Moving the participation agenda forward. Children EF Society, Hoboken, NJ: Wiley-Blackwell, v. 18, n. 2, p. 77-96, 2004.

Hood, S.; Kelley, P.; Mayall, B. Children as research subjects: a risky enterprise. Children E' Society, Hoboken, NJ: Wiley-Blackwell, v. 10, p. 117-128, 1996.

Horton,J. “Do you get some funny looks when you tell people what you do?” Muddling through some angsts and ethics of (being a male) researching with children. Ethics, Place E' Environment, United Kingdom: Taylor \& Francis, v. 4, n. 2, p. 159-166, 2001. James, A. Giving voice to children's voices: practices and problems, pitfalls and potencials. American Anthropologist, Hoboken, NJ: Wiley-Blackwell, v. 109, n. 2, p. 261-272, 2007.

; Jenks, C.; Prout, A. Theorizing childhood. Cambridge: Polity Press, 1998.

; Prout, A. (Eds.). Constructing and reconstructing childhood: contemporany issues in the sociological study of childhood. London: The Falmer Press, 1990.

Jenks, C. Childhood. London: Routledge, 1996.

KIRK, S. Methodological and ethical issues in conducting qualitative research with children and young people: a literature review. International Journal of Nursing Studies, United Kingdom: Elsevier, v. 44, n. 7, p. 1.250-1.260, Sept. 2007.

Komulainen, S. The ambiguity of the child's "voice" in social research, Childhood, London: Sage, v. 14, n. 1, p. 11-28, 2007. 
Kramer, S. Autoria e autorização: questões éticas na pesquisa com crianças. Cadernos de Pesquisa, São Paulo: Fundação Carlos Chagas; Campinas: Autores Associados, n. 116, p. 41-59, 2002.

LeE, N. Children and society: growing up in an age of uncertainty. London: Open University Press, 2001.

Masson, J. The legal context. In: Fraser, S.; Lweis, V.; Ding, S.; Kellet, M.; Robinson, C. (Eds.). Doing research with children and young people. London: Sage Publications, 2004. p. 43-58.

McCrum, S.; Bernal, P. Interviewing children: a training pack for journalists. Devon, UK: Children's Voices, 1994.

Morrow, V. Ethical issues in collaborative research with children. In: FArrell, A. (Ed.). Ethical research with children. United Kingdom: MCGraw-Hill International, 2005. p. $150-165$.

Ethical dillemas in research with children and young people about their social environments. Children's Geographies, London: Taylor \& Francis, n. 6, p. 49-61, 2008.

.; Richards, M. The ethics of social research with children: an overview. Children Ev Society, Hoboken, NJ: Wiley-Blackwell, v. 10, p. 90-105, 1996.

Powell, M. A.; Fitzgerald, R. M.; Taylor, N.; Graham, A. International literature review: ethical issues in undertaking research with children and young people. 2012. [For the Childwatch International Research Network, Southern Cross University, Centre for Children and Young People, Lismore NSW and University of Otago, Centre for Research on Children and Families, Dunedin, NZ, 2012].

; Sмiтh, A. B. Children's participation rights in research. Childhood, London: Sage, n. 16, p. 124-142, 2009.

Prout, A. The future of childhood. London: Routledge Falmer, 2005.

Punch, S. Youth transitions and interdependent adult-child relations in rural Bolivia. Journal of Rural Studies, United Kingdom: Elsevier, v. 18, n. 2, p. 123-133, 2002.

Qvortrup, J. Childhood as a social phenomenon: an introduction to a series of national reports. Vienne: European Centre, 1991. [Eurosocial Report, v. 36]

SAntos, B. S. (Org.) Conhecimento prudente para uma vida decente: um discurso sobre as ciências revisitado. Porto: Afrontamento, 2003.

.; Meneses, M. P. Epistemologias do Sul. Coimbra: Almedina, 2009.

SAntos, S. Olhares das crianças institucionalizadas sobre os seus direitos: "Poder escolher se queria vir para aqui ou não e não me deixaram dizer, não respeitaram”. 2011. Dissertação (Mestrado) - Universidade do Minho, Braga, 2011. Disponível em: <https:// repositorium.sdum.uminho.pt/handle/1822/20087>. Acesso em: 14 abr. 2016.

Sarmento, M. Os ofícios da criança. In: Congresso Internacional "Os Mundos Sociais e Culturais da InfÂncia”, 2., 2000, Braga. Anais... Braga: Instituto de Estudos da Criança da Universidade do Minho. v. II. p. 125-145.

As culturas da infância nas encruzilhadas da $2^{a}$ Modernidade. In: SARMENTo, M. J.; Cerisara, B. Crianças e miúdos: perspectivas sociopedagógicas da infância e educação. Porto: Edições ASA, 2004. p. 9-34. 
Somerville, M. The ethical imagination: Journeys of the Human Spirit. Melbourne: University Press, 2006.

Spyrou, S. The limits of children's voices: from authenticity to critical, reflexive representation. Childhood, London: Sage, v. 18, n. 2, p. 151-165, 2011.

Thomas, N.; O'Kane, C. The ethics of participatory research with children. Children E Society, Hoboken, NJ: Wiley-Blackwell, v. 12, n. 5, p. 336-348, 2006.

TomÁs, C. "Há muitos mundos no mundo": cosmopolitismos, participação e direitos da criança. Porto: Afrontamento, 2011.

Tribuna Internacional de Nuremberg. Código de Nuremberg. [S.1.: s.n.], 1947.

Woodhead, M. Psychosocial impacts of child work: a framework for research, monitoring and intervention. International Journal of Children's Rights, n. 12, p. 321-377, 2004.

\section{SOBRE A AUTORA}

Natália Fernandes é doutora em estudos da criança pela Universidade do Minho (Portugal). Professora da mesma instituição.

E-mail: natfs@ie.uminho.pt 